2020 Global Marketing Conference at Seoul Proceedings: 1451-1452 (November 2020) https://doi.org/10.15444/GMC2020.11.03.11

\title{
SACRIFICE FOR A BRAND: THREE EXPERT VISIONS OF THE FANS RELATIONSHIPS TOWARDS A FOOTBALL CLUB
}

\author{
Ricardo Cayolla, IPAM, Portugal ${ }^{1}$ \\ Sandra Maria Correia Loureiro, Instituto Universitáro de Lisboa (ISCTE-IUL) and \\ Business research unit (BRU-IUL), Portugal ${ }^{2}$
}

\begin{abstract}
This research was carried out with the aim of contributing to understanding of the concept of sacrifice associated with marketing and the relationship between brand and consumer. Fundamentally what we want to know is, in general, what leads someone to make sacrifices for a brand. We seek a "deep understanding of the actors, interactions, sentiments, and behaviors occurring for a specific process through time" (Woodside, 2010, p. 6). The areas of philosophy, journalism and football analysis were chosen because of the broad spectrum in society. There are two main objectives: $1^{\text {st }}$ to search for a different perspective to understand the phenomenon; $2^{\text {nd }}$ to have a global idea about football and fans. This is another step towards understanding the fans, the environment, the context and also the football phenomenon in a broader perspective.
\end{abstract}

Knowing that $95 \%$ of thought is subconscious and assuming respondents' limited ability to tell their own story (Woodside, 2010, p. viii), meaningful insights can only be gained though the collection of primary data that can provide researchers with first ideas concerning problems very specific (Shiu et al., 2009). Looking for accuracy, not generality (Woodside, 2010), in order to continue the journey towards understanding deep commitment and sacrifice towards a brand, such as a football club, the interview technique was used to study not only a different perspective of the theme but also to have a global idea about football and fans, trying to capture a group of facets and features associated with the phenomenon in diverse areas and gain a broader idea of the specific case of fans and of football itself and its importance in today's society.

This research consisted of three unstructured in-depth interviews. Each interview lasted 50 to 90 minutes, averaging 70 minutes. Profiles were chosen, considering their vast knowledge in the area, their credibility, and the possibility of being interviewed. The respondents were between 44 and 85 years of age. The interviews were conducted confidentially and recorded. Considering the knowledge, education and life experience of the interviewees, the narratives were considered individually and collectively to discover patterns and particularities or singularities. To help the process of analysis, NVIVO was used and we proceeded as follows: a) one initial categorization according to the authors; b) a review by a professor, an expert in the use of NVIVO; c) new and final categorization according to the authors. The conclusions are divided in two areas: a Global Vision (holistically, universal) and a Strong Focus (individually, personal). The Global Vision concerns four themes: Democracy, Life, Media and Twilight Zone and the Strong Focus has four facets:

${ }^{1}$ ricardo.cayolla@gmail.com

2 sandramloureiro@netcabo.pt 
Family influence, the Social aspect, Emotions, and Consequences at a personal level, respectively.

Keywords: sacrifice, fans, football, brand, relationships

\section{REFERENCE}

Shiu, E., Hair, J., Bush, R., \& Ortinau, D. (2009). Qualitative Research Methods: An Overview and Focus Group. In Marketing Research. New York:McGraw-Hill.

Woodside, A. G. (2010). Case Study Research: Theory, Methods,

Practice.London:Emerald 